Review

\title{
Role of the Blood-Brain Barrier in the Formation of Brain Metastases
}

\author{
Imola Wilhelm, Judit Molnár, Csilla Fazakas, János Haskó and István A. Krizbai * \\ Institute of Biophysics, Biological Research Centre of the Hungarian Academy of Sciences, \\ Temesvári krt.62, Szeged H-6726, Hungary; E-Mails: wilhelm.imola@brc.mta.hu (I.W.); \\ molnar.judit@brc.mta.hu (J.M.); fazakas.csilla@brc.mta.hu (C.F.); hasko.janos@brc.mta.hu (J.H.) \\ * Author to whom correspondence should be addressed; E-Mail: krizbai.istvan@brc.mta.hu; \\ Tel.: +36-62-599-602; Fax: +36-62-433-133.
}

Received: 17 October 2012; in revised form: 12 December 2012 / Accepted: 14 December 2012 / Published: 11 January 2013

\begin{abstract}
The majority of brain metastases originate from lung cancer, breast cancer and malignant melanoma. In order to reach the brain, parenchyma metastatic cells have to transmigrate through the endothelial cell layer of brain capillaries, which forms the morphological basis of the blood-brain barrier (BBB). The BBB has a dual role in brain metastasis formation: it forms a tight barrier protecting the central nervous system from entering cancer cells, but it is also actively involved in protecting metastatic cells during extravasation and proliferation in the brain. The mechanisms of interaction of cancer cells and cerebral endothelial cells are largely uncharacterized. Here, we provide a comprehensive review on our current knowledge about the role of junctional and adhesion molecules, soluble factors, proteolytic enzymes and signaling pathways mediating the attachment of tumor cells to brain endothelial cells and the transendothelial migration of metastatic cells. Since brain metastases represent a great therapeutic challenge, it is indispensable to understand the mechanisms of the interaction of tumor cells with the BBB in order to find targets of prevention of brain metastasis formation.
\end{abstract}

Keywords: blood-brain barrier; cerebral endothelial cell; tight junction; paracellular transmigration; astrocyte; central nervous system; metastasis; breast cancer; lung cancer; melanoma 


\section{Introduction}

Brain metastases constitute a significant part of intracranial tumors. Only in the United States, about 170,000 metastatic brain tumors are diagnosed annually [1], whereas primary tumors represent 17,000 new cases/year. The majority of brain metastases originate from lung cancer $(40 \%-50 \%)$, breast cancer (15\%-25\%) and malignant melanoma (5\%-20\%) [2]. Among these tumors, melanoma is the one which metastasizes to the brain with one of the highest frequencies: brain metastases are diagnosed in $40 \%-50 \%$ of the cases, which, after autopsy, increase with an additional $30 \%-40 \%$. Melanoma is diagnosed in six -40 cases/100,000 inhabitants/year, causing $4 \%$ of all skin cancers and being responsible for $74 \%$ of skin cancer deaths. Of melanoma brain metastases, $49 \%$ are intraparenchymal, $22 \%$ are leptomeningeal and $32 \%$ are dural [3]. The presence of a brain metastasis represents a very poor prognosis for the patient, the five-year survival rate being below $10 \%$. The number of diagnosed melanoma cases is constantly increasing [4].

Breast cancer is the second most common type of cancer and worldwide causes more than half a million deaths annually. Breast cancer metastases to the central nervous system (CNS) include the clinically distinct situations of multiple brain metastases (78\%), solitary brain metastasis (14\%) and leptomeningeal metastases (8\%) [5]. CNS metastases occur in $10 \%-16 \%$ of stage IV patients, while they are found in $30 \%$ of patients in autopsy series [5].

The most common cause of brain metastases is lung cancer. Interestingly, small cell carcinomas, which are only $20 \%$ of all lung cancers, account for $50 \%$ of brain metastases from lung cancer. About $10 \%$ of the patients having small cell lung carcinoma initially present with brain metastases. The two-year cumulative risk rises to $\geq 50 \%$, and CNS metastases are found in up to $65 \%$ of patients at autopsy. The median survival time after brain metastasis diagnosis is four to five months [6].

Formation of metastases in distant organs involves blood or lymphatic transport of cancer cells. Since the CNS lacks a lymphatic system, the only possibility for cancer cells to reach the brain is via the blood stream. Brain metastases can be formed both in the parenchyma and the meninges. Leptomeningeal metastases resulting from solid tumors occur late and usually coexist with CNS parenchymal disease. Metastatic cells invading the CNS parenchyma, however, have to pass the blood-brain barrier (BBB).

\section{The Blood-Brain Barrier}

\subsection{Cellular Structure of the BBB}

The blood-brain barrier (BBB) is located at the level of cerebral capillaries in the forefront of the defense line of the CNS and restricts the free movement of solutes and cellular elements between the systemic circulation and neuronal tissue. The BBB is involved in the pathogenesis of a large number of CNS disorders [7,8]. The most important cellular elements of the BBB are endothelial cells, astrocytes and pericytes forming the neurovascular unit (Figure 1). 
Figure 1. Schematic structure of the blood-brain barrier. Cerebral endothelial cells - coming in contact with pericytes and astrocytes - form the morphological basis of the blood-brain barrier. Endothelial cells are interconnected by a continuous line of tight junctions. The insert shows the molecular structure of the junctional complex. $\mathrm{TJ}=$ tight junction; $\mathrm{AJ}=$ adherens junction.

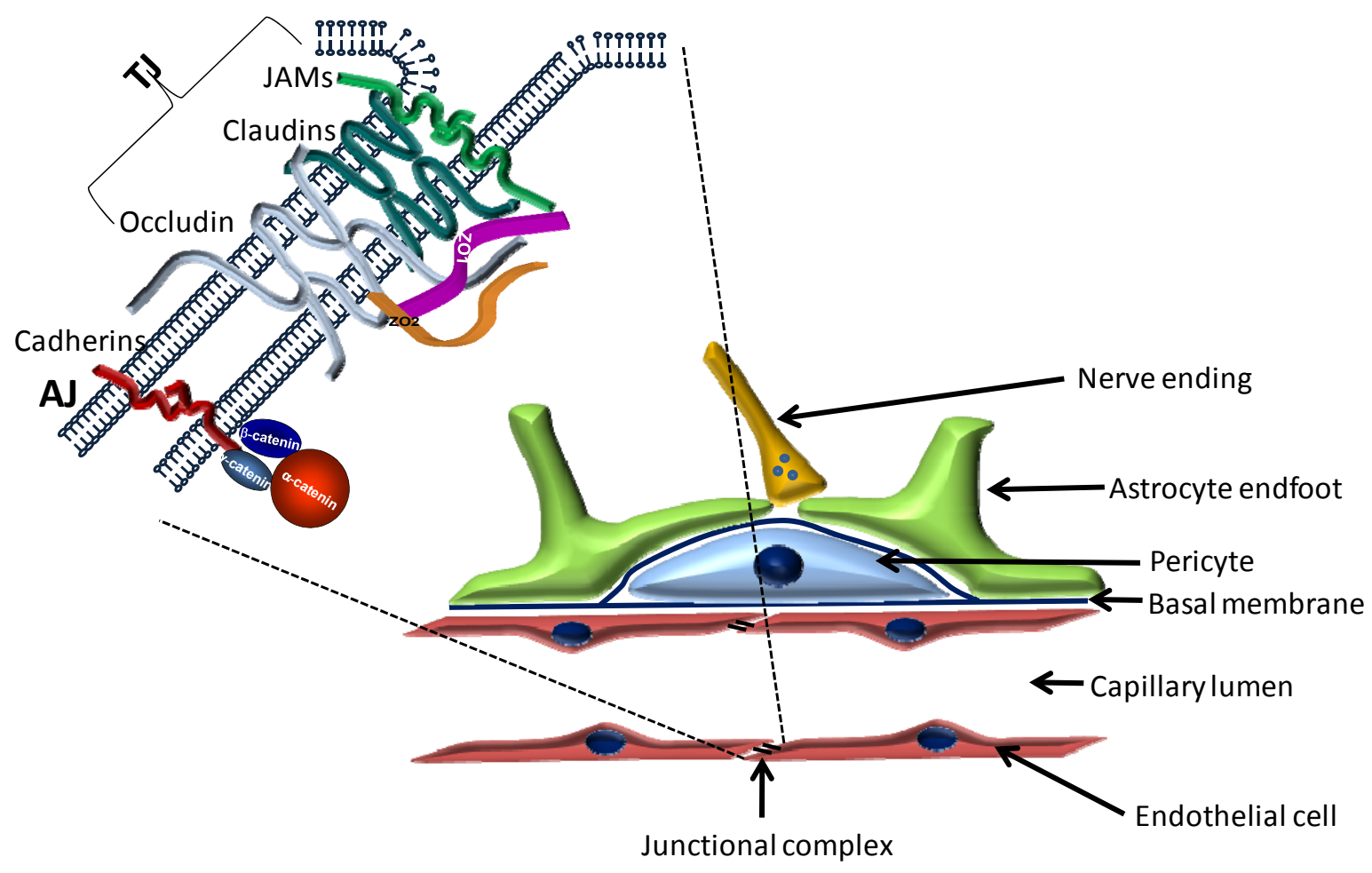

\subsubsection{Endothelial Cells}

Endothelial cells lining brain capillaries are thin, flat cells interconnected by tight junctions [9] and characterized by a high number of mitochondria [10] and low number of caveolae [11]. The contact region of brain endothelial cells is usually overlapping, and the apical region of cell membranes is interconnected by a continuous line of tight junctions limiting the free transport of different solutes and cellular elements. Cerebral endothelial cells share common features with other endothelia (presence of factor VIII, high alkaline phosphatase and $\gamma$-glutamyl transpeptidase activity, uptake of acetylated-low density lipoprotein) and epithelia as well (high transendothelial electrical resistance (TEER), continuous line of tight junctions, low level of pinocytosis), these latter being indispensable for the barrier function.

\subsubsection{Pericytes}

Pericytes are located in the duplication of the basement membrane, in close contact with endothelial cells. Even gap junctions have been described between the two cell types [12]. In the rat brain, pericyte coverage of the capillaries varies between $22 \%$ and $32 \%$ [13] and the ratio of pericyte/endothelial cells is about 1/3-5 [14]. Pericytes are contractile cells able to synthesize a plethora of biologically active substances. Although the exact function of pericytes in the formation and function of the BBB is insufficiently understood, they can participate in the regulation of blood flow, endothelial proliferation, 
angiogenesis or inflammatory processes. Absence of pericytes leads to endothelial hyperplasia, abnormal vasculogenesis [15] and increased BBB permeability [16]. Pericyte-endothelial cell interactions were found to be critical in the regulation of the BBB during development [17].

\subsubsection{Astrocytes}

Astrocytes play a crucial role in the induction of blood-brain barrier properties (reviewed in: $[18,19]$ ). Astrocytic endfeet nearly completely ensheath the capillary walls, thereby covering not only endothelial cells, but also the intimately associated pericytes [20]. The coverage is not complete, allowing a direct contact of nerve endings with the basal membrane [21,22]. Astrocytic endfeet express a high level of several specific proteins at their capillary side, like glucose transporter 1, P-glycoprotein (P-gp), aquaporin-4, connexin-43 and Kir $4.1 \mathrm{~K}^{+}$channel.

\subsubsection{Other Cells of the Neurovascular Unit}

In the adult mammalian brain, neurons are usually not in direct contact with cerebral endothelial cells. So far, it is unclear whether there are signals from endothelial cells to neurons and vice versa, which could be important for brain homeostasis or for neuronal function. Such communication could be accomplished by the presence of neurotransmitter receptors on endothelial cells, as observed previously [23].

Microglia is another cell type that is in close contact with cerebral vessels. The role of microglia in the neurovascular unit is still poorly understood, and sometimes controversial. They may potentiate BBB damage during neuroinflammation [24]; however, a beneficial effect has also been reported in response to ischaemic brain injury [25].

\subsubsection{The Basement Membrane}

The basement membrane is a specialized extracellular matrix covering endothelial cells from the outside. Its main protein components include collagen (especially type IV), fibronectin, laminin, tenascin and proteoglycans [11]. The extracellular matrix serves as an anchor for endothelial cells through the interaction between laminin and other matrix proteins and endothelial integrin receptors [26]. Besides signaling events [27], the cell-matrix interaction also modulates TJ protein expression [28]. Furthermore, the basal membrane plays an important role in cell adhesion and migration and may form a barrier for macromolecular and cellular migration. Moreover, the basal membrane was shown to be essential for the survival of cancer cells during brain colonization [29].

\subsection{Molecular Structure of the BBB}

Transport across the brain endothelium is strictly limited through a four-fold defense line (for review see: [30]): paracellular barrier (represented by interendothelial junctions); transcellular barrier (assured by the low level of endocytosis and transcytosis); enzymatic barrier (including acetylcholinesterase, alkaline phosphatase, $\gamma$-glutamyl transpeptidase, monoamine oxidases and drug metabolizing enzymes); and efflux transporters (ABC-B1, -C1, - C4, -C5 and -G2). Small gaseous molecules, such as $\mathrm{O}_{2}$ and $\mathrm{CO}_{2}$, can freely diffuse through the lipid membranes, and this is also a route 
of entry for small lipophilic agents, including barbiturates, nicotine and ethanol. However, specific blood-to-brain influx transport systems exist to supply nutrients, like glucose, amino acids and nucleotides, which cannot freely diffuse to the brain.

The paracellular permeability is mainly regulated by the tight junctions (TJs) between endothelial cells (Figure 1). Key components of the tight junctions are the transmembrane proteins, which form three protein families. These are the four transmembrane proteins (occludin, claudins, tricellulin/marvelD2, marvelD3), which are perhaps the most important from the point of view of paracellular permeability, molecules belonging to the immunoglobulin superfamily (JAM-Junctional adhesion molecule; CAR - Coxsackie and adenovirus receptor; ESAM-Endothelial cell-selective adhesion molecule) and non-immunoglobulin-like molecules with a single transmembrane domain (CRB3 - Crumbs homolog 3; Bves-Blood vessel epicardial substance). Best characterized in cerebral endothelial cells are occludin, claudins and JAMs [31].

\subsubsection{Transmembrane TJ Proteins}

\subsubsection{Occludin}

Occludin, the first identified transmembrane $\mathrm{TJ}$ protein [32], is a $65 \mathrm{kDa}$ molecule. It is characterized by four transmembrane regions, two extracellular loops, a shorter $\mathrm{N}$-terminal and a longer C-terminal cytoplasmic domain. The two extracellular loops are rich in tyrosine and glycine, playing a role in sealing the junctions [33,34], while the C-terminal region is important in the interaction with other junctional proteins.

\subsubsection{Claudins}

Claudins, first described by Furuse et al. [35], are small proteins (20-27 kDa), which show a similar membrane topology to occludin (short N-terminal cytoplasmic region, two extracellular loops, short C-terminal tail); however, there is no sequence homology between them. Interactions of claudins are largely determined by the C-terminal intracellular region, which contains PDZ binding domains. Furthermore, claudins are able to form homophylic interactions as well needed for the formation of tight junction strands [36]. The principal claudin in brain endothelial cells is claudin-5, but other claudins (especially claudin-1, -3 and -12) have also been detected [37]. The exact role of individual claudins is not known; absence of claudin-5 leads to a selective opening of the BBB to molecules smaller than $800 \mathrm{Da}$ [38]. Claudins play an important role in several pathologies, including cancer [39].

\subsubsection{Immunglobulin-like Molecules}

Junctional adhesion molecules (JAMs) are single-span molecules belonging to the immunoglobulin superfamily characterized by homophilic binding and two extracellular loops, first described by Martin-Padura et al. [40]. Brain endothelial cells express mainly JAM-1 (JAM-A) and JAM-3 (JAM-B) [41], but also JAM-C. They are involved in the extravasation of leukocytes. Endothelial cells also express ESAM (endothelial cell-selective adhesion molecule), another immunoglobulin-like molecule localized to the TJs. JAM-C and ESAM have been shown to promote melanoma lung metastasis formation $[42,43]$. 


\subsubsection{Other Transmembrane Proteins of the TJs}

In epithelial cells several additional components of the TJs have been identified, the expression/role of which has not been characterized in endothelial cells. These molecules include tricellulin, CAR, marvelD3 and Crumbs homolog 3 (CRB3).

\subsubsection{Peripheral Proteins of Tight Junctions}

\subsubsection{PDZ Domain Containing Proteins}

\subsection{Zonula Occludens (ZO) Proteins}

To our present knowledge, there are three members of the zonula occludens family: ZO-1 [44], ZO-2 [45] and ZO-3 [46]. ZO-3 seems to be less important in the formation of endothelial tight junctions [47]. Common structural features of the $\mathrm{ZO}$ family include three PDZ domains in the N-terminal region, a SH3 (Src homology 3) domain and an enzymatically inactive GUK (guanylate kinase) domain. ZO proteins are important scaffold proteins, but are essential in signaling processes as well $[48,49]$.

\subsection{Other Proteins Containing PDZ Domain}

The cytoplasmic plaque of the TJs contains other PDZ domain containing proteins as well. These include AF6/afadin, MUPP1 (multi-PDZ-domain protein), MAGI (membrane associated guanylate kinase inverted) $-1,-2$ and -3 and PAR-3 and -6 . These proteins also bind other proteins of the junctional complex, but their role in the regulation of endothelial TJs has not been characterized yet.

\subsubsection{Plaque Proteins without PDZ Domain}

Besides PDZ domain proteins, the junctional plaque contains cingulin, its homologue paracingulin/JACOP and a large number of signaling molecules.

\section{Mechanisms of Interaction of Tumor Cells with Brain Endothelial Cells}

The BBB, which represents the tightest endothelial barrier in the organism, forms an obstacle for the traffic of not only solutes, but cells as well. Penetration of cells into the CNS is highly limited by the $\mathrm{BBB}$; therefore, it is surprising that some cancer types give metastases preferentially to the brain. This phenomenon draws the attention to the possibility that besides being a barrier, the BBB may have a supportive role in the metastasis formation as well. Indeed, cerebral endothelial cells can actively take part in the transmigration process and may even facilitate the penetration of metastatic cells or can provide an ideal milieu for transmigrated cells to survive in their close proximity. This can be due to the fact that after crossing the barrier, metastatic cells are protected from the immune surveillance of the organism and cellular components of the BBB may release substances favorable for metastasis growth, as discussed in the forthcoming chapters.

Despite an impressive amount of data regarding motility and migration of cancer cells, information about the mechanisms involved in the migration of cancer cells across endothelial barriers is limited. 
This is especially true for the BBB. The process of transendothelial migration has been intensively studied using immune cells. Although the steps of transmigration (rolling, adhesion and transmigration/diapedesis) may show some similarities, due to different physiological, molecular and mechanical characteristics of immune and metastatic cells, there may be significant differences [50].

\subsection{Morphological Aspects}

Arrest of tumor cells was found to take place at the level of capillaries and postcapillary venules, where the diameter of the vessels is comparable to those of the metastatic cells, predominantly at vessel branches [51,52].

The extravasation process of tumor cells seems to have organ-specific elements. Tumor cells need a significantly longer time to extravasate into the brain than into other organs. In the brain, reaching an extraluminal position was found to take two days in case of lung and two-seven days in case of breast cancer cells [51,53]. Kienast et al. [52] have observed that melanoma and lung cancer cells have extravasated up to 14 days; however, cancer cells that later proliferated into macrometastases had left the blood vessel by the third day. The diapedesis itself is probably rapid [53], but arrested cancer cells need to survive within the brain vasculature for a significantly longer time than in other organs [51]. This seems to be a rate limiting step only in the brain. Intravascular proliferation preceding transendothelial migration seems to characterize only some cell lines with high affinity for the brain [51].

Cancer cells arrested in the brain vasculature initially assume an elongated shape and, later, round up and stretch the vessel walls [51]. During the transmigration process, tumor cells show intra- and extra-vascular parts with a narrowing at the level of the vascular wall, suggesting that the transmigration takes places through holes in the endothelium. In addition, tumor cells produce extensions and retractions of the extravascular protrusions, indicating that the transmigration process is a dynamic one [52].

The contribution of endothelial cells seems to be organ-specific as well: while in the lung and liver, endothelial cells migrate onto the surface of the tumor cells, in the brain, endothelial cells do not cover tumor cells; instead, a retraction of endothelial cells was observed [53]. It is a question of debate whether tumor cells leave the endothelium intact or destruct the vessel wall during diapedesis. Breast cancer cells were found to transmigrate at sites of discontinuity of the vessel wall, but no endothelial apoptosis or hypoxia was observed [51]. Using an in vitro system, we have observed that melanoma cells damaged the integrity of the brain endothelial monolayer, induced endothelial apoptosis and decreased the transendothelial electrical resistance [54]. It was suggested, however, that the barrier can repair after passage of metastatic cells [55]. On the other hand-although extravasation of single cells is the dominant mechanism of brain metastasis formation-in some cases, intravascular proliferation of tumor cells may lead to the complete obstruction of the vessel and, finally, to the disruption of the BBB [56].

After diapedesis, endothelial cells are indispensable for the proliferation of metastatic cells, formation of the tumor vasculature (by angiogenesis or vessel cooption) and of the blood-tumor barrier. Proliferation of metastatic cells in the brain was only observed when transmigrated metastatic cells remained in close contact to the basolateral side of endothelial cells, in a position similar to pericytes [52]. Moreover, breast cancer cells extravasated into the brain were shown to get aligned 
along the blood vessels, on the extraluminal side [56]. According to our observations, after completing the transendothelial migration process, melanoma cells continue their movement beneath the endothelial cell layer [54]. Some perivascularly located single metastatic cells (or clusters up to three) can remain dormant for longer periods [52]. These cells can constitute a source for the formation of new metastases.

The long-lasting close contact of extravasated tumor cells with the endothelium may have two reasons. First, the vascular basement membrane supports the growth of the metastasis prior to the formation of the tumor vasculature [29]. This is the so-called vessel cooption, which seems to be characteristic to breast cancer and melanoma, but not lung cancer cells [29,52,57]. In contrast to melanoma and breast cancer, lung cancer metastases were shown to present early angiogenesis [52].

Second, cancer cells might benefit from the protection of the BBB against anti-tumoral immune cells and chemotherapeutics. It is a question of debate whether the vascular network of the metastases exhibits altered permeability. The blood-tumor barrier was suggested to remain intact in small metastases, its integrity altering only when larger lesions are formed [55]. Others state that in breast cancer metastases, the blood-tumor barrier has an increased permeability, which poorly correlates with the size of the lesion. However, the barrier remains sufficiently intact to impair drug delivery [58].

The morphological aspects of the interaction of tumor cells with the brain endothelium are summarized in Figure 2a.

\subsection{Selectively Expressed Genes and Proteins in Brain Metastatic Cells}

One of the crucial issues in the goal to prevent or reduce the number of metastases is the understanding of molecular mechanisms of organ-specific metastases. A key determinant of the site of metastasis formation is the gene or protein expression profile of metastatic cells with affinity to a specific organ. Specific gene expression combinations may determine the ideal conditions in which the tumor cell can survive and divide, thus determining preferential target organs. On the other hand, in the case of the brain - which has a specific vasculature lined by BBB endothelial cells - these expression profiles may determine the interaction of metastatic cells with the endothelium as well.

In one of the first attempts to identify differentially expressed genes, the authors compared gene expression of primary lung adenocarcinoma (a frequent subtype of non-small cell lung carcinoma) with brain metastases originating from these tumors. They have found considerable differences: of 23,040 genes tested, 244 showed a different expression level, including genes coding for plasma membrane proteins, cellular antigens and cytoskeletal proteins, which may modulate cell-cell interactions [59].

Brain metastases of lung adenocarcinoma were evaluated in another study as well, by comparing the gene expression profile of metastatic brain tumors originating from lung adenocarcinoma with that of healthy lung. Using cDNA microarray technology, 1,561 differently expressed genes were found. The overexpression of certain genes associated with invasion and metastasis (PTEN, MMP1), adhesion (integrin $\alpha_{3}$ and fibronectin1), angiogenesis (VEGF) and cell migration (Rho GTPase) was validated by real-time PCR [60].

A correlation analysis of frozen samples from 142 patients diagnosed with non-small cell lung carcinoma revealed three genes that were associated with brain metastases. Expression of these three 
genes was predictive for brain metastases: FALZ (fetal Alzheimer antigen), KIFC1 (kinesin family member involved in cell proliferation) and N-cadherin. While the first two may play a role in the growth of metastases in a neural environment, expression of $\mathrm{N}$-cadherin may play a role in the interaction of metastatic cells with brain endothelial cells as well, which are also able to express N-cadherin [61].

In another study, a multidimensional proteomic analysis was used to examine the protein expression profiles of breast cancer cells, by comparing the parental cell line and its brain or bone homing variants. More than 300 proteins were found to be uniquely regulated in brain metastatic breast cancer cells, most of which are involved in cellular metabolism and cell stress response. These data reflect the adaptation of the tumor cells to aerobic glycolysis, which is more favorable in the brain environment [62].

Figure 2. Mechanisms of interaction between tumor cells and the brain endothelium. (a) Morphological aspects and upregulated genes and proteins involved in brain metastasis formation of melanoma, breast and lung cancer; (b) Molecular mechanisms. Several adhesion molecules were shown to be involved in the adhesion of tumor cells to the brain endothelium. Proteases and other soluble factors secreted by tumor cells may induce the disruption of the tight junctions.

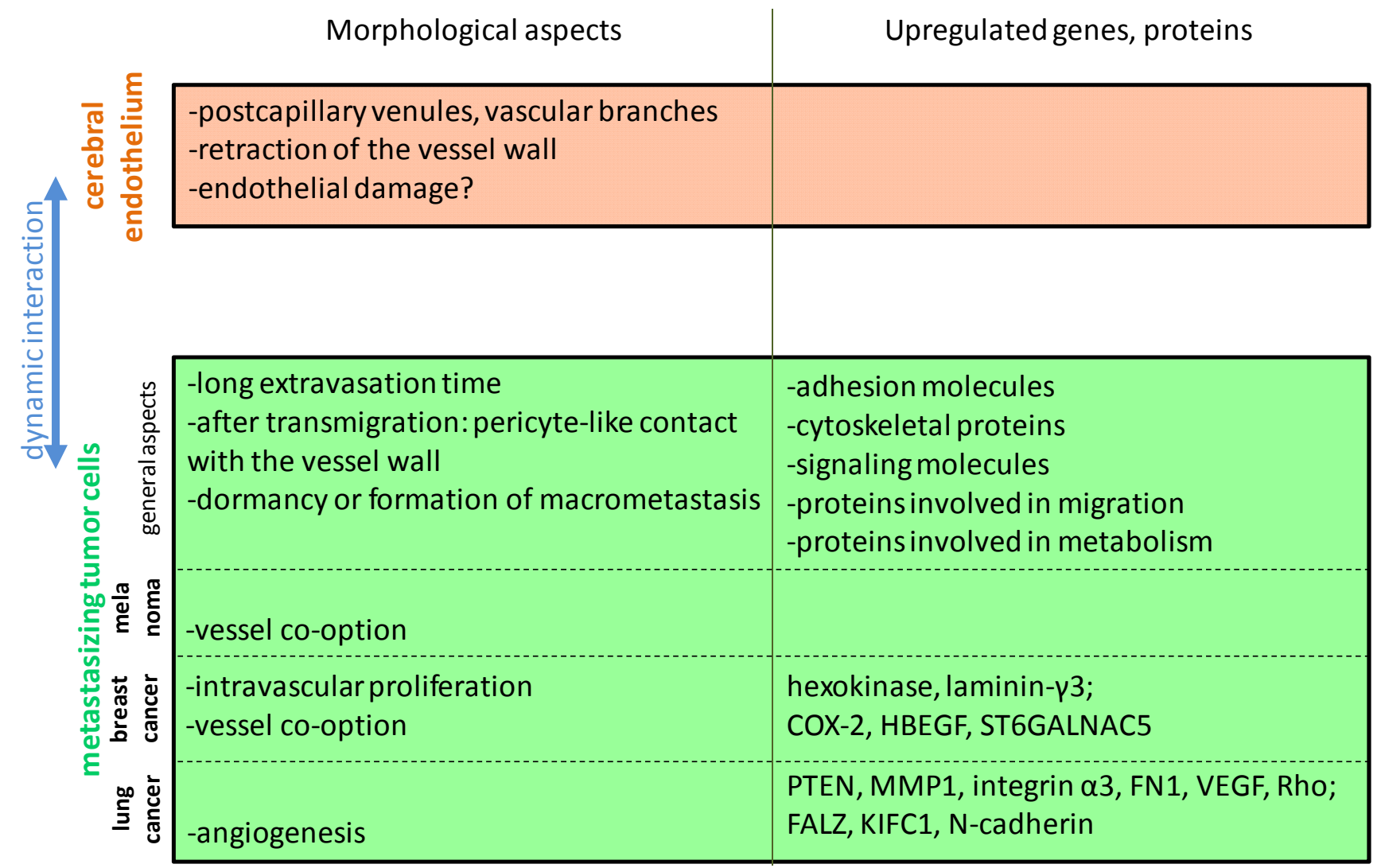

(a) 
Figure 2. Cont.

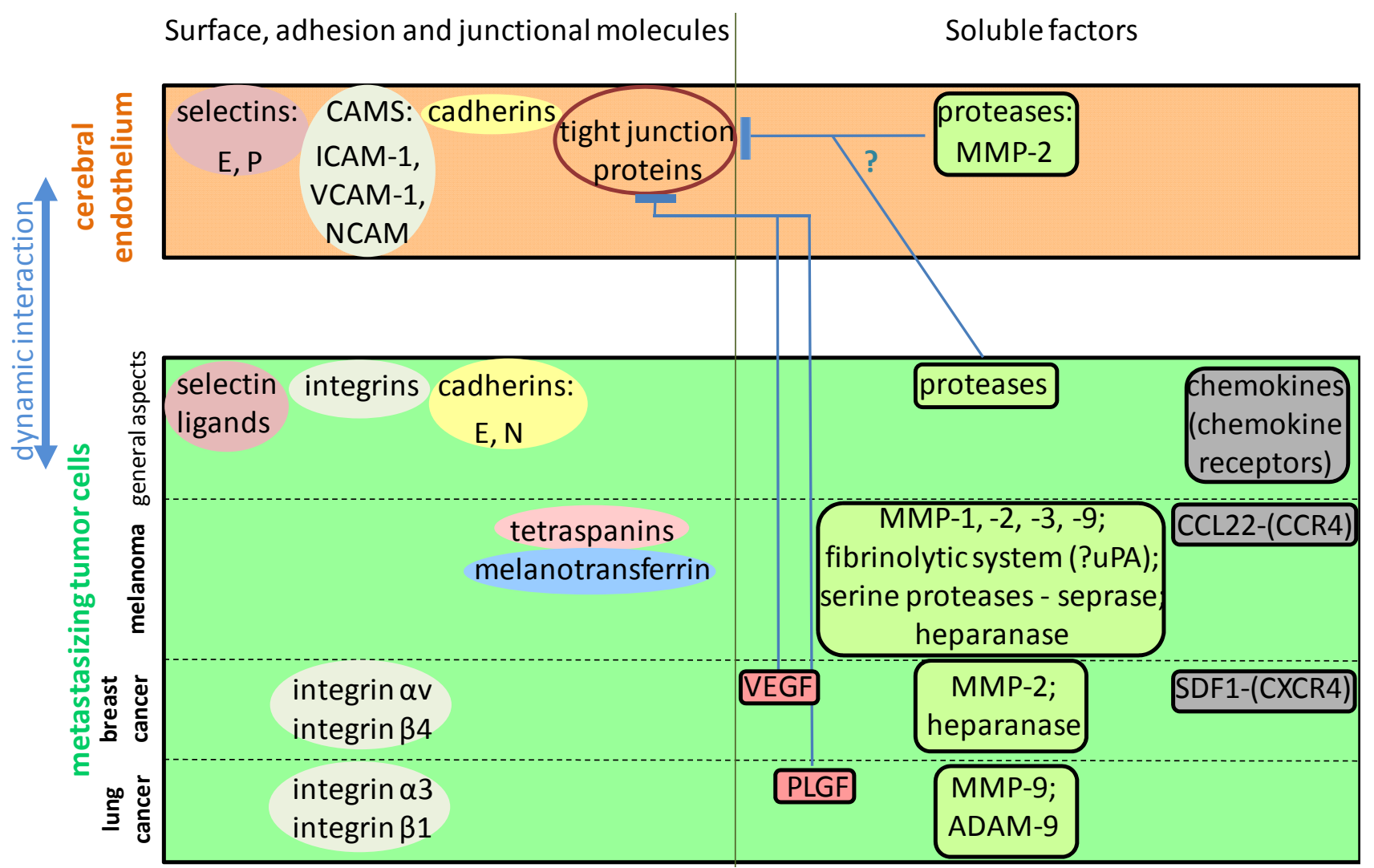

(b)

Brain and bone metastases of breast cancer cells were compared by Klein et al. [63] as well. 73 differentially expressed genes were found, with 51 genes having significantly higher expression in brain metastases. Among the genes overexpressed in the brain, several encode proteins involved in translation, metabolism, signal transduction and transport, but there are adhesion molecules as well, which may play a role in the interaction of metastatic cells with the cerebral endothelium.

Investigating breast cancer brain metastases, Palmieri et al. [64] have revealed downregulation of six genes and upregulation of two: hexokinase and laminin- $\gamma 3$.

Finally, in a genomewide comparative study, the authors have found 243 genes over- or under-expressed in the brain metastatic population of breast cancer cells. Further analysis identified COX2, the epidermal growth factor receptor ligand HBEGF, and the $\alpha 2,6$-sialyltransferase ST6GALNAC5 as important determinants of transmigration of breast cancer cells through the BBB. While COX2 and HBEFG were also found in lung metastases, ST6GALNAC5 was found to be specific to brain metastases. ST6GALNAC5 is a brain-specific sialyltransferase and may directly influence breast cancer cell adhesion to cerebral endothelial cells [65].

Summarizing the results, one can observe that the different studies have found some members of gene classes involved in adhesion and proliferation to be increased in brain metastatic tumor cells (Figure 2a). It is noteworthy, however, that there is a low overlap between the different sets of genes identified. Which of these are involved in the interaction of tumor cells and brain endothelial cells still needs to be elucidated. 


\subsection{Transmigration Routes: Role of the Proteins of the Tight Junctions}

Transendothelial migration of cells can occur by two routes: the paracellular pathway (through the interendothelial junctions) and the transcellular one (through single endothelial cells). Leukocytes are able to use both routes in the brain endothelium as well [66,67], and the molecular mechanisms involved in the paracellular and transcellular migration pathways of leukocyte diapedesis have been intensively studied (reviewed in: [68,69]). Much less is known about the transmigration routes of tumor cells, especially in the brain.

Paracellular transmigration of metastatic cells is possible only with the involvement of endothelial tight junctions and junctional proteins. In a recent study using an in vitro model of the BBB, we have observed that different types of melanoma cells were able to reduce transendothelial electrical resistance (TEER), which is a widely used indicator of junctional integrity [54]. Moreover, not only the presence of metastatic cellular elements, but their conditioned media, was also able - although to a lesser extent - to reduce TEER. Immunfluorescence studies revealed that the disruption of the TJs stands at the molecular basis of the increased permeability, reflected by a discontinuous staining of claudin-5 and ZO-1. After longer coculture times, melanoma cells were able to make holes in the endothelial monolayer, which could be used by other metastatic cells. The mechanisms by which metastatic cells are able to disrupt TJs are incompletely understood; however, proteolytic processes probably play an important role.

On the other hand, it is not excluded that tumor cells might also use the transcellular pathway; especially as brain endothelial cells are interconnected by tight junctions, which seal the intercellular way of transport. So far, transcellular migration of tumor cells has only been described in the case of intravasation of breast cancer cells into an artificial vascular network prepared from calf pulmonary artery endothelial cells [70].

\subsection{Surface Molecules Mediating Different Steps of Tumor Cell Extravasation in the Brain}

Adhesion and junctional molecules involved in tumor cell-endothelial cell interaction and metastasis formation are weakly characterized and even less is known about brain endothelial-specific mechanisms. It is well known that tumor cells are able to partly mimic the molecular mechanisms of leukocyte-endothelial interaction occurring during inflammation. The steps of transendothelial migration of leukocytes and tumor cells are principally the same, i.e., rolling, adhesion and diapedesis; however, on the molecular level, the transmigration process of tumor cells has been much less described [50]. In this interaction, surface molecules of both endothelial and tumor cells might be involved (Figure 2a). Moreover, tumor cells were shown to indirectly use the adhesion molecules of leukocytes and platelets, by attaching to them and using them as bridges to the endothelium, making the molecular aspect even more complex [71,72]. In this chapter, we review the surface molecules of both endothelial and tumor cells involved in the interaction of tumor cells with brain endothelial cells.

\subsubsection{The Role of Selectins and Selectin Ligands}

Selectin-dependent mechanisms mediate tethering and rolling of leukocytes during the first steps of extravasation. Cancer cells, similar to leukocytes, express selectin ligands, which may play an 
important role in their adhesion to endothelial cells. Selectin-dependent mechanisms are also important in the interaction of tumor cells with platelets and leukocytes, which facilitate the attachment of tumor cells to the vessel wall. The role of selectins in brain metastasis formation is largely uncharacterized. Anti-E-selectin antibodies were shown to partly inhibit adhesion of primary prostate carcinoma cells to brain endothelial cells [73]. Moreover, heparin—which inhibits not only coagulation, but selectin-mediated interactions as well — was shown to delay melanoma brain metastasis formation. Therefore, it has been suggested that heparin might have an anti-metastatic neuroprotective role, which might depend on selectins [74].

\subsubsection{Integrins Involved in the Interaction of Tumor Cells with the Brain Endothelium}

Integrins are heterodimeric proteins consisting of a $\alpha$ and a $\beta$ subunit that mediate cell-cell and cell-extracellular matrix interactions. They facilitate the firm adhesion of leukocytes to the endothelium. Several integrins were shown to be involved in cancer progression, metastasis formation, transendothelial migration of tumor cells and angiogenesis in different metastatic sites. Activation of integrin $\alpha_{\mathrm{v}} \beta_{3}$ was observed to support efficient brain metastatic growth of breast cancer cells through continuous upregulation of VEGF, without influencing the growth of primary lesions [75]. Moreover, intetumumab, an anti-integrin $\alpha_{\mathrm{v}}$ monoclonal antibody, prevents brain metastasis formation of breast cancer cells [76]. Interaction of breast cancer cells with the brain endothelium might also be dependent on integrin $\beta_{4}$. Integrin $\beta_{4}$ signaling is involved not by directly promoting the adhesion of tumor cells to the endothelium, but by enhancing the HER2-dependent expression of VEGF, which induces the disruption of interendothelial junctions [77]. In the case of non-small cell lung cancer, the interaction of integrin $\alpha_{3} \beta_{1}$ and laminin was suggested to play an important role in brain metastasis formation [78]. Blockade or loss of $\beta_{1}$ integrin in mammary carcinoma cells prevents metastasis establishment and growth of the tumor cells in the CNS [29].

\subsubsection{The Role of the Immunglobulin Superfamily of Cell Adhesion Molecules}

Endothelial cells express several adhesion molecules belonging to the immunoglobulin (Ig) superfamily, including members of the intercellular adhesion molecules (ICAMs), vascular-cell adhesion molecule (VCAM-1), platelet-endothelial-cell adhesion molecule (PECAM-1) and junctional adhesion molecules (JAMs). These are essential in immune response and inflammation, but some of them were also shown to be involved in the interaction of vascular endothelial and tumor cells and formation of metastases. Anti-VCAM-1 antibodies were shown to partly inhibit adhesion of primary prostate carcinoma cells to brain endothelial cells [73]. Moreover, establishment of pulmonary melanoma metastases was found to be followed by increases in VCAM-1 expression in organs frequently affected by melanoma metastases, including the brain [79]. In a recent paper, ICAM-1 and VCAM-1 were shown to play a crucial role in polychlorinated biphenyl-mediated enhancement of brain metastasis formation of lung carcinoma cells [80]. NCAM was shown to be highly expressed in the primary tumors of brain metastasis patients [81]; However, brain metastases were found to lose NCAM expression [82]. This may suggest that NCAM is important for the formation of brain metastasis (e.g., for transendothelial migration of tumor cells into the brain) and not for the survival or proliferation of metastatic cells in the brain environment. 


\subsubsection{Cadherins}

Cadherins are $\mathrm{Ca}^{2+}$-dependent cell adhesion molecules fundamental in tissue organization. Cadherin dysfunction is involved in tumor progression and metastasis formation. Loss of expression of E-cadherin induces epithelial-mesenchymal transition in carcinoma cells, which initiates an increase in cell motility and metastasis formation. In metastatic lesions, a re-expression of E-cadherin has been observed, which plays an important role in the proliferation of tumor cells at the metastatic site. Correspondingly, metastatic brain tumors were shown to express high levels of E-cadherin [83-85], while low expression of E-cadherin in primary non-small cell lung carcinomas was shown to correlate with increased risk for the development of brain metastasis [86]. In non-small cell lung carcinomas, the expression level of $\mathrm{N}$-cadherin was observed to be highly predictive of brain metastasis formation [61]. Since transendothelial migration of melanoma cells through human lung microvascular endothelial cells was found to involve N-cadherin-mediated adhesion [87], a similar mechanism is possible in the case of brain endothelial cells as well. N-cadherin was shown to be recruited to the contact sites between transmigrating melanoma cells and pulmonary endothelial cells, followed by its Src kinase-mediated phosphorylation and dissociation of $\beta$-catenin from $\mathrm{N}$-cadherin [88].

\subsubsection{Tetraspanins}

Several members of the tetraspanin superfamily, including CD9, CD81 and CD151, might localize at the tumor cell-endothelial cell heterologous contact area. Among these, endothelial CD9 was shown to actively redistribute to points of melanoma insertion, and anti-CD9 antibodies were found to inhibit migration of melanoma cells through HUVEC monolayers [89]. CD151-null mice showed a markedly diminished number of experimental lung metastasis after injection of Lewis lung carcinoma or B16F10 melanoma cells [90]. Similar mechanisms might be involved in the transmigration of tumor cells through the BBB as well.

\subsubsection{Melanotransferrin}

Melanotransferrin has been identified as a surface molecule on melanoma cells. Expression of melanotransferrin was found to correlate with increased transmigration of melanoma cells through the $\mathrm{BBB}$, while blocking melanotransferrin significantly reduced transmigration. In mediating the effect of melanotransferrin, the plasmin-metalloproteinase system could be involved [91].

\subsection{Soluble Factors Affecting Brain Metastasis Formation}

Tumor cells secrete several factors that may enhance their migration through the brain endothelium (Figure 2b). Brain-derived soluble factors may also play a significant role in the formation of brain metastases. This may be true especially in the case of melanoma, where the high proportion of brain metastases may be due to a "homing" influence [92], because melanocytes and the nervous system share a common embryologic (ectodermal) origin. 


\subsubsection{Neurotrophins}

Neurotrophins (NTs: NGF, BDNF, NT-3 and NT-4/5) are growth factors promoting neuronal survival, differentiation and cell death. Invasive and survival properties of CNS-metastatic melanoma cells were shown to be dependent on the presence of particular NTs that can be secreted by different cell types within the CNS. Brain metastatic melanoma cells may induce the production of brain NTs that aid in the survival and invasion of melanoma cells in the CNS [93]. In addition, NGF enhances the production of extracellular matrix-degradative enzymes in melanoma cells [92].

In the brain, NTs and NT receptors are known to be expressed by neurons and astrocytes. However, recent data suggest that NT release and signaling in the CNS may not be restricted to these two cell types. Murine and rat brain endothelial cell lines were shown to express NGF, BDNF and two NT receptors (TrkA and p75) [94,95]. Furthermore, pericytes are also able to express NGF and BDNF [96]. Therefore, one can speculate whether NTs play a role not only in the survival and proliferation of metastatic melanoma cells in the CNS, but in their migration through the BBB as well.

\subsubsection{Chemokines}

An important role in the formation of brain metastases seems to have chemokines and their receptors as well. In a recent comprehensive study, melanoma cells were shown to express a whole set of chemokine receptors, including CCR3, CCR4, CXCR3, CXCR7, CX3CR1 and membrane CX3CL1. Among these receptors, the expression of CCR4 was found to be significantly higher in a brain metastatic melanoma variant. Activation of CCR4 by its ligand CCL22 induced a specific Akt phosphorylation pattern, suggesting that specific signaling may be related to brain metastasis formation [97]. Moreover, brain-derived soluble factors were able to upregulate the expression of CCR3 and CCR4 in melanoma cells and enhanced the transmigration of melanoma cells through a monolayer of cerebral microvascular endothelial cells [98], further indicating that the brain microenvironment is not only important for the growth of already formed brain metastases, but also for the transmigration of melanoma cells through the BBB. Chemokines seem to be important in the brain metastasis formation of breast cancer cells as well, since the CXCR4/SDF1 signaling pathway was shown to have a decisive role in the migration of breast cancer cells through brain endothelial monolayers [99].

\subsubsection{Vascular Endothelial Growth Factor and Its Receptors}

Being a key modulator of angiogenesis, VEGF is a well-established factor in the growth of metastases. However, VEGF secreted by extravasating tumor cells may be involved in the transmigration process as well, mainly by enhancing the permeability. In breast cancer cells, HER2 increases VEGF protein production, which induces the disruption of interendothelial junctions [77]. In addition, VEGF was shown to increase the adhesion of highly metastatic MDA-MB-231 breast cancer cells to brain endothelial monolayers and to enhance their transmigration through an in vitro BBB model [100]. It has also been shown that small cell lung cancer cell-derived placental growth factor activates the VEGFR1/Rho/ERK signaling pathway in cerebral endothelial cells, resulting in the disassembly of tight junctions and promoting transendothelial migration [101]. 


\subsection{Proteases Involved in the Formation of CNS Metastases}

Proteolytic enzymes may play a role in several steps of metastasis formation, including invasion at the primary tumor site, intravasation, extravasation and metastatic colonization. Different proteolytic enzymes have been implicated in brain metastasis formation and migration of tumor cells through blood-brain barrier endothelial cells. The proteases involved are matrix metalloproteinases (MMPs), serine proteases and heparanase. These enzymes are mainly secreted by tumor cells; however, endothelial cells or astrocytes might also be induced by tumor cells to express proteases.

\subsubsection{The Role of Matrix Metalloproteinases in the Formation of Brain Metastases}

Several results suggest that MMP-2 plays a key role in the brain metastasis formation of breast cancer cells [102-104], melanoma [105] and leukemic cells [106]. MMP-3 and MMP-9 are also implicated in the development of breast cancer brain metastases [103]. In addition, MMP-1 and MMP-9 were shown to be overexpressed in brain-seeking breast cancer cells in comparison with bone-seeking variants [107], while expression of MMP-2 and MMP-9 was found to be upregulated in breast cancer cells treated with angiotensin II, probably contributing to the increased migration through brain endothelial cells [108]. MMP-9 was found to be overexpressed by brain metastatic lung adenocarcinoma cells [109].

Regarding transendothelial migration of tumor cells through the BBB, MMPs might have special importance, because TJ proteins can be targets of MMP degradation. MMP-induced disruption of TJs was shown to promote invasion of tumor cells into the CNS [106]. Interestingly, not only tumor cells themselves produce MMPs, but they are able to induce the expression of proteases in brain endothelial cells, e.g., MMP-2 was shown to be induced in brain endothelial cells after coculture with breast cancer cells [110]. In this study COX-2 and MMP-2 produced by cerebral endothelial cells was found to facilitate the extravasation of breast cancer cells across the BBB.

\subsubsection{Other Proteases}

ADAM-9, a member of the "a disintegrin and metalloprotease" (ADAM) family was found to be overexpressed in highly brain-metastatic non-small cell lung cancer sublines in comparison with parent or highly bone-metastatic sublines [111]. In melanoma, plasmin was proved to be a key determinant of crossing of the BBB and formation of brain metastasis [112]. Moreover, we have shown that during migration of melanoma cells through the brain endothelium, tumor cells release large amounts of gelatinolytic serine proteases, including seprase. Inhibition of these proteases or silencing of seprase could significantly reduce the number of extravasating melanoma cells [54].

\subsubsection{Heparanase}

Heparanase is an endoglycosidase, degrading heparan sulfate proteoglycans, being a critical mediator of tumor cell proliferation, angiogenesis, invasion and metastasis. This is achieved by remodeling of the extracellular matrix, releasing growth factors, chemokines, angiogenic factors, bioactive cell-surface heparin sulfate fragments and through non-enzymatic (signaling) activities [113]. Heparanase is considered a critical molecular determinant of brain metastasis [114] in melanoma [115] 
and breast cancer [116], but surprisingly high exogenous heparanase concentrations were shown to downregulate invasion of brain metastatic melanoma cells [117]. Besides tumor cells, astrocytes were found to produce heparanase as well, significantly contributing to the brain colonization of melanoma cells [118].

\subsection{Signaling Pathways Involved in Tumor-endothelial Interactions in the Brain}

In order to be able to respond adequately to extracellular stimuli, cerebral endothelial cells are equipped with a whole set of receptors and signaling molecules [119-121], reviewed in: [122]. This may contribute to a considerable heterogeneity of cerebral endothelial cells as well [123]. Transendothelial migration of tumor cells requires the active involvement of both tumor and endothelial cells. Understanding the pathways activated both in tumor cells and in endothelial cells will help to identify molecular targets for cancer therapy.

\subsubsection{Rho/Rac Signaling}

During invasion of tissues and migration through vessel walls and ECM components, metastasizing tumor cells require increased motility, which is dependent on the remodeling of the cytoskeleton. In this respect, members of the Rho family small GTPases were shown to have an indispensable role by regulating the two major modes of tumor cell movement, characterized by mesenchymal and amoeboid phenotype. The mesenchymal type of tumor cell movement requires elevated Rac1 activation and reduced Rho/ROCK signaling and is characterized by elongated cell morphology, formation of large membrane protrusions and dependence on integrins and extracellular proteolysis. On the other hand, the amoeboid migration type mimics movement of leukocytes, with a rounded morphology and generation of Rho/ROCK-dependent actomyosin contractile forces [124-126]. Interplay between these two types of tumor cell motility was shown to regulate movement of tumor cells during invasion of the extracellular matrix; however, little is known about the behavior of tumor cells meeting other types of barriers, i.e., during intravasation into circulation and extravasation into diverse tissues, including transmigration through the BBB. It has been shown that inhibition of ROCK decreases the migration of small cell lung cancer cells through the brain endothelium [127]. This effect, however, is not due to changes in tumor cell movement, since Rho/ROCK signaling, cytoskeletal reorganization and the concomitant changes of the tight junctions of endothelial cells were responsible for the decrease of transendothelial migration of tumor cells. This, in turn, highlights the importance of endothelial cells in the extravasation of tumor cells, clearly indicating that the endothelium forms not only a passive barrier for metastatic cells, but takes an active part in the process.

\subsubsection{Src Signaling}

Src family members are known to participate in many aspects of tumor progression and metastasis. In tumor cells, Src kinase may participate in the promotion of mesenchymal and inhibition of amoeboid motility [128] and in the phosphorylation of $\mathrm{N}$-cadherin and dissociation of $\beta$-catenin during transendothelial migration [88]. Src kinases are known to regulate interendothelial junctions and 
endothelial permeability as well $[129,130]$; therefore, it would be interesting to understand whether (brain) endothelial Src signaling is involved in metastasis formation.

\subsubsection{The PI3K-Akt-PTEN Pathway}

The PI3K-Akt pathway is a crucial regulator of cell survival and proliferation, and increased PI3K activity has been reported in several cancer types. In a recent study, a novel inhibitor of downstream PI3K was found to effectively control metastatic growth of HER2 positive breast cancer cells in multiple organs and resulted in a significant proportion of mice free from brain and bone metastases [131]. In addition, brain metastases of melanoma were shown to have significantly higher levels of phosphorylated Akt and lower PTEN than lung or liver metastases [132]. This pathway was shown to be activated not only in brain metastatic melanoma cells, but also in brain endothelial cells coming in contact with melanoma cell-conditioned media, inducing increased endothelial cell proliferation and motility [133]. Moreover, the PI3K inhibitor LY294002 was shown to reduce the number of ECM-invading breast cancer cells in the presence of pulmonary microvascular endothelial cells [134]. It was also shown that melanoma cell-associated VE-cadherin breakdown in HUVECs was not sensitive to LY294002, whereas transendothelial migration of melanoma cells was reduced in the presence of the PI3K inhibitor [135]. However, inhibition of PI3K had no effect on the transmigration of small cell lung cancer cells through brain endothelial cells [127].

\subsubsection{Other Pathways Implicated in Brain Metastasis Formation, Transendothelial Migration or Invasion of Brain Metastatic Tumor Cells}

In the search for the determinants of brain metastasis formation, a few other signaling pathways have been described, which might be involved in the migration of tumor cells through the BBB. Recently, overexpression of endothelin receptor B was shown to result in an increased incidence of spontaneous CNS metastases of melanoma [136]. In melanoma, TGF- $\beta 2$ was found to be crucial as well, since its expression is indispensable for the formation of parenchymal metastases [137]. Stat3 activation was found to play an important role in angiogenesis, invasion and brain metastasis formation of melanoma cells through dysregulated expression of bFGF, VEGF and MMP-2 [105]. In breast cancer cells HER2 (EGFR2), positivity was found to contribute to brain metastatic colonization [138], the HER2 transfectants giving a significantly increased number of macrometastases. Taking into account that the BBB prevents the delivery of trastuzumab (a HER2 monoclonal antibody used for the treatment of mammary tumors), HER2 positive breast cancer patients have an increased risk of mortality caused by brain metastases. Besides HER2 positivity, breast cancers with increased risk to develop brain metastasis are more likely to be estrogen receptor negative, to express the basal cytokeratin CK5/6 and to overexpress EGFR [139]. Mutations in EGFR have been implicated in the pathogenesis of another brain metastasis-giving tumor type, the non-small cell lung carcinoma. An increased risk of progression in the CNS was found in advanced non-small cell lung cancer with EGFR mutations [140]. In lung adenocarcinoma, activation of the canonical WNT/TCF pathway through LEF1 and HOXB9 was identified as a key element of metastasis formation to brain and bone [141].

There are several signaling mechanisms implicated in the proliferation, invasion or migration of tumor cells, which-although not investigated so far - might be involved in the migration of tumor 
cells through the BBB. The multidrug transporter P-glycoprotein, for example, has been shown to mediate the invasion of melanoma cells. P-gp was shown to cooperate with CD44 through the activation of MAP-kinases, leading to increased MMP activities [142]. Moreover, the MAP-kinase signaling pathways (including the mutations in BRAF) are critical in the development and progression of primary and brain metastatic melanoma; however, their role in the transendothelial migration of tumor cells has not been documented. ERK1/2 was shown to be activated in brain endothelial cells coming in contact with melanoma cell-conditioned media [133]. In melanoma, another pathway, phospholipase $\mathrm{C}$ signaling, might also be important, since it was shown to be involved in melanoma cell-induced endothelial junction disassembly in HUVECs [135]. Other promising targets might be receptor tyrosine kinases, e.g., Axl, which is highly expressed in several tumor types, including brain metastatic tumors [143] and cerebral endothelial cells as well [144]. Axl confers aggressive tumor behavior, leading to dissemination and metastasis formation [145]; however, no data are available about the role of Axl in brain metastasis formation.

\subsection{Role of Astrocytes in Brain Metastasis Formation}

Astrocytes have an indispensable role in the maintenance of BBB properties of cerebral endothelial cells. Therefore, they support endothelial cells in impeding tumor cells from penetrating into the brain. On the other hand, astrocytes have a protective role for brain metastases. Reactive astrocytes immediately localize to individual breast cancer cells even before extravasation and continue to associate with metastatic cells during the transmigration process and throughout the growth of the lesions [51]. Reactive astrocytes induce the protection of tumor cells from chemotherapy through sequestration of calcium from the cytoplasm of tumor cells and by upregulating survival genes in tumor cells $[146,147]$. Moreover, astrocytes secrete soluble factors that stimulate the proliferation of tumor cells in the brain microenvironment. In this respect, neurotrophins have a special importance in supporting the growth of melanoma cells [148]. In addition, astrocytes were shown to induce proliferation of lung and breast cancer cells by producing IL-1 $\beta$, TNF- $\alpha$ and/or IL-6 [149,150]. Since inflammation was found to foster proliferation, survival and migration of tumor cells [151] and metastatic cells are also able to use several similar transendothelial migratory mechanisms as leukocytes, it is tempting to speculate that these proinflammatory cytokines secreted by astrocytes might not only induce proliferation of tumor cells, but also support the transendothelial migration and formation of new metastatic colonies in the brain. Astrocytes also produce heparanase, which was shown to contribute to the brain-metastatic specificity of melanoma cells [118], and MMP-9, which can support invasion of tumor cells and release growth factors from the extracellular matrix [51].

\section{Conclusions}

Tumor cells meet a supportive environment in the brain parenchyma, protected from chemotherapeutics and antitumoral immune response and containing soluble factors favoring their survival and proliferation. It is not surprising, therefore, that brain metastases of malignant tumors have limited therapeutic options. Hence, it would be of crucial importance to prevent the formation of brain metastases. One of the possible strategies is to target the step of migration of metastatic cells through the blood-brain barrier. The mechanisms of this process are largely uncharacterized; however, 
besides preventing cancer cells from entering the brain, brain endothelial cells seem to also play a protective role for metastatic cells during extravasation. Understanding these mechanisms is indispensable to find targets of prevention of brain metastasis formation.

\section{Acknowledgments}

This work was supported by the Hungarian Research Fund (OTKA PD-100958, K-100807), the Hungary-Romania Cross-Border Co-operation Programme 2007-2013 (HURO/1101/173/2.2.1) and the TÁMOP-4.2.2.A-11/1/KONV-2012-0052 project. I. Wilhelm was supported by the Bolyai Fellowship.

\section{References}

1. Platta, C.S.; Khuntia, D.; Mehta, M.P.; Suh, J.H. Current treatment strategies for brain metastasis and complications from therapeutic techniques: A review of current literature. Am. J. Clin. Oncol. 2010, 33, 398-407.

2. Wen, P.Y.; Black, P.M.; Loeffler, J.S. Treatment of Metastatic Cancer. In Cancer: Principles and Practice of Oncology, 6th ed.; DeVita, V.T., Hellman, S., Rosenberg, S.A., Eds.; Lippincott and Wilkins: Philadelphia, PA, USA, 2011.

3. Fidler, I.J.; Schackert, G.; Zhang, R.D.; Radinsky, R.; Fujimaki, T. The biology of melanoma brain metastasis. Cancer Metastasis Rev. 1999, 18, 387-400.

4. Douglas, J.G.; Margolin, K. The treatment of brain metastases from malignant melanoma. Semin. Oncol. 2002, 29, 518-524.

5. Pestalozzi, B.C. Brain metastases and subtypes of breast cancer. Ann. Oncol. 2009, 20, 803-805.

6. Meert, A.P.; Paesmans, M.; Berghmans, T.; Martin, B.; Mascaux, C.; Vallot, F.; Verdebout, J.M.; Lafitte, J.J.; Sculier, J.P. Prophylactic cranial irradiation in small cell lung cancer: A systematic review of the literature with meta-analysis. BMC Cancer 2001, 1, doi:10.1186/1471-2407-1-5.

7. Neuwelt, E.; Abbott, N.J.; Abrey, L.; Banks, W.A.; Blakley, B.; Davis, T.; Engelhardt, B.; Grammas, P.; Nedergaard, M.; Nutt, J.; et al. Strategies to advance translational research into brain barriers. Lancet Neurol. 2008, 7, 84-96.

8. Stolp, H.B.; Dziegielewska, K.M. Review: Role of Developmental inflammation and blood-brain barrier dysfunction in neurodevelopmental and neurodegenerative diseases. Neuropathol. Appl. Neurobiol. 2009, 35, 132-146.

9. Brightman, M.W.; Reese, T.S. Junctions between intimately apposed cell membranes in the vertebrate brain. J. Cell Biol. 1969, 40, 648-677.

10. Oldendorf, W.H.; Cornford, M.E.; Brown, W.J. The large apparent work capability of the blood-brain barrier: A study of the mitochondrial content of capillary endothelial cells in brain and other tissues of the rat. Ann. Neurol. 1977, 1, 409-417.

11. The Blood-Brain Barrier, Biology and Research Protocols; Nag, S., Ed.; Humana Press: Totowa, NJ, USA, 2003; p. 572.

12. Cuevas, P.; Gutierrez-Diaz, J.A.; Reimers, D.; Dujovny, M.; Diaz, F.G.; Ausman, J.I. Pericyte endothelial gap junctions in human cerebral capillaries. Anat. Embryol. 1984, 170, 155-159.

13. Sims, D.E. Recent Advances in pericyte biology_Implications for health and disease. Can. J. Cardiol. 1991, 7, 431-443. 
14. Pardridge, W.M. Blood-brain barrier biology and methodology. J. Neurovirol. 1999, 5, 556-569.

15. Hellstrom, M.; Gerhardt, H.; Kalen, M.; Li, X.; Eriksson, U.; Wolburg, H.; Betsholtz, C. Lack of pericytes leads to endothelial hyperplasia and abnormal vascular morphogenesis. J. Cell Biol. 2001, 153, 543-553.

16. Armulik, A.; Genove, G.; Mae, M.; Nisancioglu, M.H.; Wallgard, E.; Niaudet, C.; He, L.; Norlin, J.; Lindblom, P.; Strittmatter, K.; et al. Pericytes regulate the blood-brain barrier. Nature 2010, 468, 557-561.

17. Daneman, R.; Zhou, L.; Kebede, A.A.; Barres, B.A. Pericytes are required for blood-brain barrier integrity during embryogenesis. Nature 2010, 468, 562-566.

18. Abbott, N.J.; Ronnback, L.; Hansson, E. Astrocyte-endothelial interactions at the blood-brain barrier. Nat. Rev. Neurosci. 2006, 7, 41-53.

19. Krizbai, I.; Wilhelm, I.; Bauer, H.C.; Bauer, H. The Role of Glia in the Formation and Function of the Blood-Brain Barrier. In Neuroglia, 3rd ed.; Kettenmann, H., Ransom, B.R., Eds.; Oxford University Press: Oxford, UK, 2012.

20. Kacem, K.; Lacombe, P.; Seylaz, J.; Bonvento, G. Structural organization of the perivascular astrocyte endfeet and their relationship with the endothelial glucose transporter: A confocal microscopy study. Glia 1998, 23, 1-10.

21. Cohen, Z.; Molinatti, G.; Hamel, E. Astroglial and vascular interactions of noradrenaline terminals in the rat cerebral cortex. J. Cereb. Blood Flow Metab. 1997, 17, 894-904.

22. Paspalas, C.D.; Papadopoulos, G.C. Ultrastructural relationships between noradrenergic nerve fibers and non-neuronal elements in the rat cerebral cortex. Glia 1996, 17, 133-146.

23. Krizbai, I.A.; Deli, M.A.; Pestenacz, A.; Siklos, L.; Szabo, C.A.; Andras, I.; Joo, F. Expression of glutamate receptors on cultured cerebral endothelial cells. J. Neurosci. Res. 1998, 54, 814-819.

24. Nishioku, T.; Dohgu, S.; Takata, F.; Eto, T.; Ishikawa, N.; Kodama, K.B.; Nakagawa, S.; Yamauchi, A.; Kataoka, Y. Detachment of brain pericytes from the basal lamina is involved in disruption of the blood-brain barrier caused by lipopolysaccharide-induced sepsis in mice. Cell. Mol. Neurobiol. 2009, 29, 309-316.

25. Denes, A.; Vidyasagar, R.; Feng, J.; Narvainen, J.; McColl, B.W.; Kauppinen, R.A.; Allan, S.M. Proliferating resident microglia after focal cerebral ischaemia in mice. J. Cereb. Blood Flow Metab. 2007, 27, 1941-1953.

26. Hynes, R.O. Integrins: Versatility, modulation, and signaling in cell adhesion. Cell 1992, 69, 11-25.

27. Tilling, T.; Engelbertz, C.; Decker, S.; Korte, D.; Huwel, S.; Galla, H.J. Expression and adhesive properties of basement membrane proteins in cerebral capillary endothelial cell cultures. Cell Tissue Res. 2002, 310, 19-29.

28. Savettieri, G.; di Liegro, I.; Catania, C.; Licata, L.; Pitarresi, G.L.; D’Agostino, S.; Schiera, G.; de Caro, V.; Giandalia, G.; Giannola, L.I.; et al. Neurons and ECM regulate occludin localization in brain endothelial cells. Neuroreport 2000, 11, 1081-1084.

29. Carbonell, W.S.; Ansorge, O.; Sibson, N.; Muschel, R. The vascular basement membrane as "soil" in brain metastasis. PLoS One 2009, 4, e5857, doi:10.1371/journal.pone.0005857.

30. Wilhelm, I.; Fazakas, C.; Krizbai, I.A. In vitro models of the blood-brain barrier. Acta Neurobiol. Exp. 2011, 71, 113-128. 
31. Bauer, H.C.; Traweger, A.; Zweimueller-Mayer, J.; Lehner, C.; Tempfer, H.; Krizbai, I.; Wilhelm, I.; Bauer, H. New aspects of the molecular constituents of tissue barriers. J. Neural Transm. 2011, 118, 7-21.

32. Furuse, M.; Hirase, T.; Itoh, M.; Nagafuchi, A.; Yonemura, S.; Tsukita, S.; Tsukita, S. Occludin: A novel integral membrane protein localizing at tight junctions. J. Cell Biol. 1993, 123, 1777-1788.

33. Wong, V.; Gumbiner, B.M. A synthetic peptide corresponding to the extracellular domain of occludin perturbs the tight junction permeability barrier. J. Cell Biol. 1997, 136, 399-409.

34. Lacaz-Vieira, F.; Jaeger, M.M.; Farshori, P.; Kachar, B. Small synthetic peptides homologous to segments of the first external loop of occludin impair tight junction resealing. J. Membr. Biol. 1999, 168, 289-297.

35. Furuse, M.; Fujita, K.; Hiiragi, T.; Fujimoto, K.; Tsukita, S. Claudin-1 and -2: Novel integral membrane proteins localizing at tight junctions with no sequence similarity to occludin. J. Cell Biol. 1998, 141, 1539-1550.

36. Piontek, J.; Winkler, L.; Wolburg, H.; Muller, S.L.; Zuleger, N.; Piehl, C.; Wiesner, B.; Krause, G.; Blasig, I.E. Formation of tight junction: Determinants of homophilic interaction between classic claudins. FASEB J. 2008, 22, 146-158.

37. Ohtsuki, S.; Yamaguchi, H.; Katsukura, Y.; Asashima, T.; Terasaki, T. MRNA expression Levels of tight junction protein genes in mouse brain capillary endothelial cells highly purified by magnetic cell sorting. J. Neurochem. 2008, 104, 147-154.

38. Nitta, T.; Hata, M.; Gotoh, S.; Seo, Y.; Sasaki, H.; Hashimoto, N.; Furuse, M.; Tsukita, S. Size-selective loosening of the blood-brain barrier in claudin-5-deficient mice. J. Cell Biol. 2003, 161, 653-660.

39. Ouban, A.; Ahmed, A.A. Claudins in human cancer: A review. Histol. Histopathol. 2010, 25, 83-90.

40. Martin-Padura, I.; Lostaglio, S.; Schneemann, M.; Williams, L.; Romano, M.; Fruscella, P.; Panzeri, C.; Stoppacciaro, A.; Ruco, L.; Villa, A.; et al. Junctional adhesion molecule, a novel member of the immunoglobulin superfamily that distributes at intercellular junctions and modulates monocyte transmigration. J. Cell Biol. 1998, 142, 117-127.

41. Aurrand-Lions, M.; Johnson-Leger, C.; Wong, C.; Du Pasquier, L.; Imhof, B.A. Heterogeneity of endothelial junctions is reflected by differential expression and specific subcellular localization of the three JAM family members. Blood 2001, 98, 3699-3707.

42. Langer, H.F.; Orlova, V.V.; Xie, C.; Kaul, S.; Schneider, D.; Lonsdorf, A.S.; Fahrleitner, M.; Choi, E.Y.; Dutoit, V.; Pellegrini, M.; et al. A novel function of junctional adhesion molecule-c in mediating melanoma cell metastasis. Cancer Res. 2011, 71, 4096-4105.

43. Cangara, H.M.; Ishida, T.; Hara, T.; Sun, L.; Toh, R.; Rikitake, Y.; Kundu, R.K.; Quertermous, T.; Hirata, K.; Hayashi, Y. Role of Endothelial cell-selective adhesion molecule in hematogeneous metastasis. Microvasc. Res. 2010, 80, 133-141.

44. Stevenson, B.R.; Siliciano, J.D.; Mooseker, M.S.; Goodenough, D.A. Identification of ZO-1: A high molecular weight polypeptide associated with the tight junction (zonula occludens) in a variety of epithelia. J. Cell Biol. 1986, 103, 755-766.

45. Gumbiner, B.; Lowenkopf, T.; Apatira, D. Identification of a $160-\mathrm{kDa}$ polypeptide that binds to the tight junction protein ZO-1. Proc. Natl. Acad. Sci. USA 1991, 88, 3460-3464. 
46. Haskins, J.; Gu, L.; Wittchen, E.S.; Hibbard, J.; Stevenson, B.R. ZO-3, a novel member of the maguk protein family found at the tight junction, interacts with ZO-1 and occludin. J. Cell Biol. 1998, 141, 199-208.

47. Inoko, A.; Itoh, M.; Tamura, A.; Matsuda, M.; Furuse, M.; Tsukita, S. Expression and distribution of ZO-3, a tight junction MAGUK protein, in mouse tissues. Genes Cells 2003, 8 , 837-845.

48. Balda, M.S.; Matter, K. The tight junction protein ZO-1 and an interacting transcription factor regulate ErbB-2 expression. EMBO J. 2000, 19, 2024-2033.

49. Traweger, A.; Fuchs, R.; Krizbai, I.A.; Weiger, T.M.; Bauer, H.C.; Bauer, H. The tight junction protein ZO-2 localizes to the nucleus and interacts with the heterogeneous nuclear ribonucleoprotein scaffold attachment factor-B. J. Biol. Chem. 2003, 278, 2692-2700.

50. Strell, C.; Entschladen, F. Extravasation of leukocytes in comparison to tumor cells. Cell. Commun. Signal. 2008, 6, doi:10.1186/1478-811X-6-10.

51. Lorger, M.; Felding-Habermann, B. Capturing changes in the brain microenvironment during initial steps of breast cancer brain metastasis. Am. J. Pathol. 2010, 176, 2958-2971.

52. Kienast, Y.; von Baumgarten, L.; Fuhrmann, M.; Klinkert, W.E.; Goldbrunner, R.; Herms, J.; Winkler, F. Real-time imaging reveals the single steps of brain metastasis formation. Nat. Med. 2010, 16, 116-122.

53. Paku, S.; Dome, B.; Toth, R.; Timar, J. Organ-specificity of the extravasation process: An ultrastructural study. Clin. Exp. Metastasis 2000, 18, 481-492.

54. Fazakas, C.; Wilhelm, I.; Nagyoszi, P.; Farkas, A.E.; Hasko, J.; Molnar, J.; Bauer, H.; Bauer, H.C.; Ayaydin, F.; Dung, N.T.; et al. Transmigration of melanoma cells through the blood-brain barrier: Role of endothelial tight junctions and melanoma-released serine proteases. PLoS One 2011, 6, e20758, doi:10.1371/journal.pone.0020758.

55. Fidler, I.J. The role of the organ microenvironment in brain metastasis. Semin. Cancer Biol. 2011, 21, 107-112.

56. Lu, W.; Bucana, C.D.; Schroit, A.J. Pathogenesis and vascular integrity of breast cancer brain metastasis. Int. J. Cancer 2007, 120, 1023-1026.

57. Barnhill, R.L.; Benson, P.J.; Lugassy, C. Conspicuous angiotropism of malignant melanoma involving the brain: Implications for extravascular migratory metastasis. Am. J. Dermatopathol. 2009, 31, 205-208.

58. Lockman, P.R.; Mittapalli, R.K.; Taskar, K.S.; Rudraraju, V.; Gril, B.; Bohn, K.A.; Adkins, C.E.; Roberts, A.; Thorsheim, H.R.; Gaasch, J.A.; et al. Heterogeneous blood-tumor barrier permeability determines drug efficacy in experimental brain metastases of breast cancer. Clin. Cancer Res. 2010, 16, 5664-5678.

59. Kikuchi, T.; Daigo, Y.; Ishikawa, N.; Katagiri, T.; Tsunoda, T.; Yoshida, S.; Nakamura, Y. Expression profiles of metastatic brain tumor from lung adenocarcinomas on cDNA microarray. Int. J. Oncol. 2006, 28, 799-805.

60. Zohrabian, V.M.; Nandu, H.; Gulati, N.; Khitrov, G.; Zhao, C.; Mohan, A.; Demattia, J.; Braun, A.; Das, K.; Murali, R.; et al. Gene expression profiling of metastatic brain cancer. Oncol. Rep. 2007, 18, 321-328. 
61. Grinberg-Rashi, H.; Ofek, E.; Perelman, M.; Skarda, J.; Yaron, P.; Hajduch, M.; Jacob-Hirsch, J.; Amariglio, N.; Krupsky, M.; Simansky, D.A.; et al. The expression of three genes in primary non-small cell lung cancer is associated with metastatic spread to the brain. Clin. Cancer Res. 2009, 15, 1755-1761.

62. Chen, E.I.; Hewel, J.; Krueger, J.S.; Tiraby, C.; Weber, M.R.; Kralli, A.; Becker, K.; Yates, J.R.,3rd; Felding-Habermann, B. Adaptation of energy metabolism in breast cancer brain metastases. Cancer Res. 2007, 67, 1472-1486.

63. Klein, A.; Olendrowitz, C.; Schmutzler, R.; Hampl, J.; Schlag, P.M.; Maass, N.; Arnold, N.; Wessel, R.; Ramser, J.; Meindl, A.; et al. Identification of brain- and bone-specific breast cancer metastasis genes. Cancer Lett. 2009, 276, 212-220.

64. Palmieri, D.; Fitzgerald, D.; Shreeve, S.M.; Hua, E.; Bronder, J.L.; Weil, R.J.; Davis, S.; Stark, A.M.; Merino, M.J.; Kurek, R.; et al. Analyses of resected human brain metastases of breast cancer reveal the association between up-regulation of hexokinase 2 and poor prognosis. Mol. Cancer. Res. 2009, 7, 1438-1445.

65. Bos, P.D.; Zhang, X.H.; Nadal, C.; Shu, W.; Gomis, R.R.; Nguyen, D.X.; Minn, A.J.; van de Vijver, M.J.; Gerald, W.L.; Foekens, J.A.; et al. Genes that mediate breast cancer metastasis to the brain. Nature 2009, 459, 1005-1009.

66. Wolburg, H.; Wolburg-Buchholz, K.; Engelhardt, B. Diapedesis of mononuclear cells across cerebral venules during experimental autoimmune encephalomyelitis leaves tight junctions intact. Acta Neuropathol. 2005, 109, 181-190.

67. Reijerkerk, A.; Kooij, G.; van der Pol, S.M.; Khazen, S.; Dijkstra, C.D.; de Vries, H.E. Diapedesis of monocytes is associated with mmp-mediated occludin disappearance in brain endothelial cells. FASEB J. 2006, 20, 2550-2552.

68. Dejana, E. The transcellular railway: Insights into leukocyte diapedesis. Nat. Cell Biol. 2006, 8, 105-107.

69. Carman, C.V. Mechanisms for transcellular diapedesis: Probing and pathfinding by 'invadosomelike protrusions'. J. Cell. Sci. 2009, 122, 3025-3035.

70. Khuon, S.; Liang, L.; Dettman, R.W.; Sporn, P.H.; Wysolmerski, R.B.; Chew, T.L. Myosin light chain kinase mediates transcellular intravasation of breast cancer cells through the underlying endothelial cells: A three-dimensional FRET study. J. Cell. Sci. 2010, 123, 431-440.

71. Konstantopoulos, K.; Thomas, S.N. Cancer cells in transit: The vascular interactions of tumor cells. Annu. Rev. Biomed. Eng. 2009, 11, 177-202.

72. Gay, L.J.; Felding-Habermann, B. Contribution of platelets to tumour metastasis. Nat. Rev. Cancer 2011, 11, 123-134.

73. Brayton, J.; Qing, Z.; Hart, M.N.; VanGilder, J.C.; Fabry, Z. Influence of adhesion molecule expression by human brain microvessel endothelium on cancer cell adhesion. J. Neuroimmunol. 1998, 89, 104-112.

74. Maraveyas, A.; Johnson, M.J.; Xiao, Y.P.; Noble, S. Malignant melanoma as a target malignancy for the study of the anti-metastatic properties of the heparins. Cancer Metastasis Rev. 2010, 29, $777-784$. 
75. Lorger, M.; Krueger, J.S.; O'Neal, M.; Staflin, K.; Felding-Habermann, B. Activation of tumor cell integrin alphavbeta3 controls angiogenesis and metastatic growth in the brain. Proc. Natl. Acad. Sci. USA 2009, 106, 10666-10671.

76. Wu, Y.J.; Muldoon, L.L.; Gahramanov, S.; Kraemer, D.F.; Marshall, D.J.; Neuwelt, E.A. Targeting alpha(V)-integrins decreased metastasis and increased survival in a nude rat breast cancer brain metastasis model. J. Neurooncol. 2012, 110, 27-36.

77. Fan, J.; Cai, B.; Zeng, M.; Hao, Y.; Giancotti, F.G.; Fu, B.M. Integrin beta4 signaling promotes mammary tumor cell adhesion to brain microvascular endothelium by inducing ErbB2-mediated secretion of VEGF. Ann. Biomed. Eng. 2011, 39, 2223-2241.

78. Yoshimasu, T.; Sakurai, T.; Oura, S.; Hirai, I.; Tanino, H.; Kokawa, Y.; Naito, Y.; Okamura, Y.; Ota, I.; Tani, N.; et al. Increased expression of integrin alpha3beta1 in highly brain metastatic subclone of a human non-small cell lung cancer cell line. Cancer. Sci. 2004, 95, 142-148.

79. Langley, R.R.; Carlisle, R.; Ma, L.; Specian, R.D.; Gerritsen, M.E.; Granger, D.N. Endothelial expression of vascular cell adhesion molecule-1 correlates with metastatic pattern in spontaneous melanoma. Microcirculation 2001, 8, 335-345.

80. Sipos, E.; Chen, L.; Andras, I.E.; Wrobel, J.; Zhang, B.; Pu, H.; Park, M.; Eum, S.Y.; Toborek, M. Proinflammatory adhesion molecules facilitate polychlorinated biphenyl-mediated enhancement of brain metastasis formation. Toxicol. Sci. 2012, 126, 362-371.

81. Onodera, H.; Nagayama, S.; Tachibana, T.; Fujimoto, A.; Imamura, M. Brain metastasis from colorectal cancer. Int. J. Colorectal Dis. 2005, 20, 57-61.

82. Duenisch, P.; Reichart, R.; Mueller, U.; Brodhun, M.; Bjerkvig, R.; Romeike, B.; Walter, J.; Herbold, C.; Regenbrecht, C.R.; Kalff, R.; et al. Neural cell adhesion molecule isoform 140 declines with rise of who grade in human gliomas and serves as indicator for the invasion zone of multiform glioblastomas and brain metastases. J. Cancer Res. Clin. Oncol. 2011, 137, 399-414.

83. Shabani, H.K.; Kitange, G.; Tsunoda, K.; Anda, T.; Tokunaga, Y.; Shibata, S.; Kaminogo, M.; Hayashi, T.; Ayabe, H.; Iseki, M. Immunohistochemical expression of e-cadherin in metastatic brain tumors. Brain Tumor Pathol. 2003, 20, 7-12.

84. Chao, Y.L.; Shepard, C.R.; Wells, A. Breast carcinoma cells re-express E-cadherin during mesenchymal to epithelial reverting transition. Mol. Cancer. 2010, 9, doi:10.1186/1476-4598-9-179.

85. Zeljko, M.; Pecina-Slaus, N.; Martic, T.N.; Kusec, V.; Beros, V.; Tomas, D. Molecular alterations of E-cadherin and beta-catenin in brain metastases. Front. Biosci. 2011, 3, 616-624.

86. Yoo, J.Y.; Yang, S.H.; Lee, J.E.; Cho, D.G.; Kim, H.K.; Kim, S.H.; Kim, I.S.; Hong, J.T.; Sung, J.H.; Son, B.C.; et al. E-cadherin as a predictive marker of brain metastasis in non-small-cell lung cancer, and its regulation by pioglitazone in a preclinical model. J. Neurooncol. 2012, 109, 219-227.

87. Qi, J.; Chen, N.; Wang, J.; Siu, C.H. Transendothelial migration of melanoma cells involves $\mathrm{N}$-cadherin-mediated adhesion and activation of the beta-catenin signaling pathway. Mol. Biol. Cell 2005, 16, 4386-4397.

88. Qi, J.; Wang, J.; Romanyuk, O.; Siu, C.H. Involvement of Src family kinases in N-cadherin phosphorylation and beta-catenin dissociation during transendothelial migration of melanoma cells. Mol. Biol. Cell 2006, 17, 1261-1272. 
89. Longo, N.; Yanez-Mo, M.; Mittelbrunn, M.; de la Rosa, G.; Munoz, M.L.; Sanchez-Madrid, F.; Sanchez-Mateos, P. Regulatory role of tetraspanin CD9 in tumor-endothelial cell interaction during transendothelial invasion of melanoma cells. Blood 2001, 98, 3717-3726.

90. Takeda, Y.; Li, Q.; Kazarov, A.R.; Epardaud, M.; Elpek, K.; Turley, S.J.; Hemler, M.E. Diminished metastasis in tetraspanin CD151-knockout mice. Blood 2011, 118, 464-472.

91. Rolland, Y.; Demeule, M.; Fenart, L.; Beliveau, R. Inhibition of melanoma brain metastasis by targeting melanotransferrin at the cell surface. Pigment Cell. Melanoma Res. 2009, 22, 86-98.

92. Aucoin, R.; Marchetti, D. Brain metastases in melanoma: Roles of neurotrophins. Neuro Oncol. 2004, 6, 154-165.

93. Nicolson, G.L.; Menter, D.G. Trophic factors and central nervous system metastasis. Cancer Metastasis Rev. 1995, 14, 303-321.

94. Kim, H.; Li, Q.; Hempstead, B.L.; Madri, J.A. Paracrine and autocrine functions of brain-derived neurotrophic factor (BDNF) and nerve growth factor (NGF) in brain-derived endothelial cells. J. Biol. Chem. 2004, 279, 33538-33546.

95. Lecht, S.; Arien-Zakay, H.; Kohan, M.; Lelkes, P.I.; Lazarovici, P. Angiostatic effects of K252a, a Trk inhibitor, in murine brain capillary endothelial cells. Mol. Cell. Biochem. 2010, 339, 201-213.

96. Shimizu, F.; Sano, Y.; Abe, M.A.; Maeda, T.; Ohtsuki, S.; Terasaki, T.; Kanda, T. Peripheral nerve pericytes modify the blood-nerve barrier function and tight junctional molecules through the secretion of various soluble factors. J. Cell. Physiol. 2011, 226, 255-266.

97. Izraely, S.; Klein, A.; Sagi-Assif, O.; Meshel, T.; Tsarfaty, G.; Hoon, D.S.; Witz, I.P. Chemokine-chemokine receptor axes in melanoma brain metastasis. Immunol. Lett. 2010, 130, 107-114.

98. Klein, A.; Sagi-Assif, O.; Izraely, S.; Meshel, T.; Pasmanik-Chor, M.; Nahmias, C.; Couraud, P.O.; Erez, N.; Hoon, D.S.; Witz, I.P. The metastatic microenvironment: Brain-derived soluble factors alter the malignant phenotype of cutaneous and brain-metastasizing melanoma cells. Int. J. Cancer 2012, 131, 2509-2518.

99. Lee, B.C.; Lee, T.H.; Avraham, S.; Avraham, H.K. Involvement of the chemokine receptor CXCR4 and its ligand stromal cell-derived factor 1alpha in breast cancer cell migration through human brain microvascular endothelial cells. Mol. Cancer Res. 2004, 2, 327-338.

100. Lee, T.H.; Avraham, H.K.; Jiang, S.; Avraham, S. Vascular endothelial growth factor modulates the transendothelial migration of MDA-MB-231 breast cancer cells through regulation of brain microvascular endothelial cell permeability. J. Biol. Chem. 2003, 278, 5277-5284.

101. Li, B.; Wang, C.; Zhang, Y.; Zhao, X.Y.; Huang, B.; Wu, P.F.; Li, Q.; Li, H.; Liu, Y.S.; Cao, L.Y.; et al. Elevated PLGF contributes to small-cell lung cancer brain metastasis. Oncogene 2012, doi:10.1038/onc.2012.313.

102. Tester, A.M.; Waltham, M.; Oh, S.J.; Bae, S.N.; Bills, M.M.; Walker, E.C.; Kern, F.G.; Stetler-Stevenson, W.G.; Lippman, M.E.; Thompson, E.W. Pro-matrix metalloproteinase-2 transfection increases orthotopic primary growth and experimental metastasis of MDA-MB-231 human breast cancer cells in nude mice. Cancer Res. 2004, 64, 652-658.

103. Mendes, O.; Kim, H.T.; Stoica, G. Expression of MMP2, MMP9 and MMP3 in breast cancer brain metastasis in a rat model. Clin. Exp. Metastasis 2005, 22, 237-246. 
104. Mendes, O.; Kim, H.T.; Lungu, G.; Stoica, G. MMP2 role in breast cancer brain metastasis development and its regulation by TIMP2 and ERK1/2. Clin. Exp. Metastasis 2007, 24, 341-351.

105. Xie, T.X.; Huang, F.J.; Aldape, K.D.; Kang, S.H.; Liu, M.; Gershenwald, J.E.; Xie, K.; Sawaya, R.; Huang, S. Activation of stat 3 in human melanoma promotes brain metastasis. Cancer Res. 2006, 66, 3188-3196.

106. Feng, S.; Cen, J.; Huang, Y.; Shen, H.; Yao, L.; Wang, Y.; Chen, Z. Matrix metalloproteinase-2 and -9 secreted by leukemic cells increase the permeability of blood-brain barrier by disrupting tight junction proteins. PLoS One 2011, 6, e20599, doi:10.1371/journal.pone.0020599.

107. Stark, A.M.; Anuszkiewicz, B.; Mentlein, R.; Yoneda, T.; Mehdorn, H.M.; Held-Feindt, J. Differential expression of matrix metalloproteinases in brain- and bone-seeking clones of metastatic MDA-MB-231 breast cancer cells. J. Neurooncol. 2007, 81, 39-48.

108. Rodrigues-Ferreira, S.; Abdelkarim, M.; Dillenburg-Pilla, P.; Luissint, A.C.; di-Tommaso, A.; Deshayes, F.; Pontes, C.L.; Molina, A.; Cagnard, N.; Letourneur, F.; et al. Angiotensin II facilitates breast cancer cell migration and metastasis. PLoS One 2012, 7, e35667, doi:10.1371/ journal.pone.0035667.

109. Hu, L.; Zhang, J.; Zhu, H.; Min, J.; Feng, Y.; Zhang, H. Biological characteristics of a specific brain metastatic cell line derived from human lung adenocarcinoma. Med. Oncol. 2010, 27, 708-714.

110. Lee, K.Y.; Kim, Y.J.; Yoo, H.; Lee, S.H.; Park, J.B.; Kim, H.J. Human brain endothelial cell-derived COX-2 facilitates extravasation of breast cancer cells across the blood-brain barrier. Anticancer Res. 2011, 31, 4307-4313.

111. Shintani, Y.; Higashiyama, S.; Ohta, M.; Hirabayashi, H.; Yamamoto, S.; Yoshimasu, T.; Matsuda, H.; Matsuura, N. Overexpression of ADAM9 in non-small cell lung cancer correlates with brain metastasis. Cancer Res. 2004, 64, 4190-4196.

112. Perides, G.; Zhuge, Y.; Lin, T.; Stins, M.F.; Bronson, R.T.; Wu, J.K. The fibrinolytic system facilitates tumor cell migration across the blood-brain barrier in experimental melanoma brain metastasis. BMC Cancer 2006, 6, doi:10.1186/1471-2407-6-56.

113. Ilan, N.; Elkin, M.; Vlodavsky, I. Regulation, function and clinical significance of heparanase in cancer metastasis and angiogenesis. Int. J. Biochem. Cell Biol. 2006, 38, 2018-2039.

114. Marchetti, D.; Nicolson, G.L. Human heparanase: A molecular determinant of brain metastasis. Adv. Enzyme Regul. 2001, 41, 343-359.

115. Roy, M.; Marchetti, D. Cell surface heparan sulfate released by heparanase promotes melanoma cell migration and angiogenesis. J. Cell. Biochem. 2009, 106, 200-209.

116. Zhang, L.; Sullivan, P.; Suyama, J.; Marchetti, D. Epidermal growth factor-induced heparanase nucleolar localization augments DNA topoisomerase I activity in brain metastatic breast cancer. Mol. Cancer. Res. 2010, 8, 278-290.

117. Ridgway, L.D.; Wetzel, M.D.; Marchetti, D. Modulation of GEF-H1 induced signaling by heparanase in brain metastatic melanoma cells. J. Cell. Biochem. 2010, 111, 1299-1309.

118. Marchetti, D.; Li, J.; Shen, R. Astrocytes contribute to the brain-metastatic specificity of melanoma cells by producing heparanase. Cancer Res. 2000, 60, 4767-4770.

119. Deli, M.A.; Joo, F.; Krizbai, I.; Lengyel, I.; Nunzi, M.G.; Wolff, J.R. Calcium/calmodulin-stimulated protein kinase II is present in primary cultures of cerebral endothelial cells. J. Neurochem. 1993, 60, 1960-1963. 
120. Krizbai, I.; Szabo, G.; Deli, M.; Maderspach, K.; Lehel, C.; Olah, Z.; Wolff, J.R.; Joo, F. Expression of protein kinase $\mathrm{C}$ family members in the cerebral endothelial cells. J. Neurochem. 1995, 65, 459-462.

121. Fabian, G.; Szabo, C.A.; Bozo, B.; Greenwood, J.; Adamson, P.; Deli, M.A.; Joo, F.; Krizbai, I.A.; Szucs, M. Expression of G-protein subtypes in cultured cerebral endothelial cells. Neurochem. Int. 1998, 33, 179-185.

122. Krizbai, I.A.; Deli, M.A. Signalling pathways regulating the tight junction permeability in the blood-brain barrier. Cell. Mol. Biol. 2003, 49, 23-31.

123. Krizbai, I.A.; Bauer, H.; Amberger, A.; Hennig, B.; Szabo, H.; Fuchs, R.; Bauer, H.C. Growth factor-induced morphological, physiological and molecular characteristics in cerebral endothelial cells. Eur. J. Cell Biol. 2000, 79, 594-600.

124. Wolf, K.; Mazo, I.; Leung, H.; Engelke, K.; von Andrian, U.H.; Deryugina, E.I.; Strongin, A.Y.; Brocker, E.B.; Friedl, P. Compensation mechanism in tumor cell migration: Mesenchymal-amoeboid transition after blocking of pericellular proteolysis. J. Cell Biol. 2003, 160, 267-277.

125. Sahai, E.; Marshall, C.J. Differing modes of tumour cell invasion have distinct requirements for rho/rock signalling and extracellular proteolysis. Nat. Cell Biol. 2003, 5, 711-719.

126. Sanz-Moreno, V.; Gadea, G.; Ahn, J.; Paterson, H.; Marra, P.; Pinner, S.; Sahai, E.; Marshall, C.J. Rac activation and inactivation control plasticity of tumor cell movement. Cell 2008, $135,510-523$.

127. Li, B.; Zhao, W.D.; Tan, Z.M.; Fang, W.G.; Zhu, L.; Chen, Y.H. Involvement of Rho/ROCK signalling in small cell lung cancer migration through human brain microvascular endothelial cells. FEBS Lett. 2006, 580, 4252-4260.

128. Ahn, J.; Sanz-Moreno, V.; Marshall, C.J. The metastasis gene NEDD9 product acts through integrin beta3 and Src to promote mesenchymal motility and inhibit amoeboid motility. J. Cell. Sci. 2012, 125, 1814-1826.

129. Farkas, A.; Szatmari, E.; Orbok, A.; Wilhelm, I.; Wejksza, K.; Nagyoszi, P.; Hutamekalin, P.; Bauer, H.; Bauer, H.C.; Traweger, A.; et al. Hyperosmotic mannitol in-duces Src kinase-dependent phosphorylation of beta-catenin in cerebral endothelial cells. J. Neurosci. Res. 2005, 80, 855-861.

130. Takenaga, Y.; Takagi, N.; Murotomi, K.; Tanonaka, K.; Takeo, S. Inhibition of Src activity decreases tyrosine phosphorylation of occludin in brain capillaries and attenuates increase in permeability of the blood-brain barrier after transient focal cerebral ischemia. J. Cereb. Blood Flow Metab. 2009, 29, 1099-1108.

131. Nanni, P.; Nicoletti, G.; Palladini, A.; Croci, S.; Murgo, A.; Ianzano, M.L.; Grosso, V.; Stivani, V.; Antognoli, A.; Lamolinara, A.; et al. Multiorgan metastasis of human HER-2(+) breast cancer in Rag2(-)/(-);I12rg(-)/(-) mice and treatment with PI3K inhibitor. PLoS One 2012, 7, e39626, doi:10.1371/journal.pone.0039626.

132. Davies, M.A.; Stemke-Hale, K.; Lin, E.; Tellez, C.; Deng, W.; Gopal, Y.N.; Woodman, S.E.; Calderone, T.C.; Ju, Z.; Lazar, A.J.; et al. Integrated molecular and clinical analysis of AKT activation in metastatic melanoma. Clin. Cancer Res. 2009, 15, 7538-7546.

133. Anfuso, C.D.; Giurdanella, G.; Motta, C.; Muriana, S.; Lupo, G.; Ragusa, N.; Alberghina, M. PKCalpha-MAPK/ERK-phospholipase A2 signaling is required for human melanoma-enhanced brain endothelial cell proliferation and motility. Microvasc. Res. 2009, 78, 338-357. 
134. Mierke, C.T. Cancer cells regulate biomechanical properties of human microvascular endothelial cells. J. Biol. Chem. 2011, 286, 40025-40037.

135. Peng, H.H.; Hodgson, L.; Henderson, A.J.; Dong, C. Involvement of phospholipase C signaling in melanoma cell-induced endothelial junction disassembly. Front. Biosci. 2005, 10, 1597-1606.

136. Cruz-Munoz, W.; Jaramillo, M.L.; Man, S.; Xu, P.; Banville, M.; Collins, C.; Nantel, A.; Francia, G.; Morgan, S.S.; Cranmer, L.D.; et al. Roles for endothelin receptor B and BCL2A1 in spontaneous CNS metastasis of melanoma. Cancer Res. 2012, 72, 4909-4919.

137. Zhang, C.; Zhang, F.; Tsan, R.; Fidler, I.J. Transforming growth factor-beta2 is a molecular determinant for site-specific melanoma metastasis in the brain. Cancer Res. 2009, 69, 828-835.

138. Palmieri, D.; Bronder, J.L.; Herring, J.M.; Yoneda, T.; Weil, R.J.; Stark, A.M.; Kurek, R.; Vega-Valle, E.; Feigenbaum, L.; Halverson, D.; et al. Her-2 overexpression increases the metastatic outgrowth of breast cancer cells in the brain. Cancer Res. 2007, 67, 4190-4198.

139. Hicks, D.G.; Short, S.M.; Prescott, N.L.; Tarr, S.M.; Coleman, K.A.; Yoder, B.J.; Crowe, J.P.; Choueiri, T.K.; Dawson, A.E.; Budd, G.T.; et al. Breast cancers with brain metastases are more likely to be estrogen receptor negative, express the basal cytokeratin CK5/6, and overexpress HER2 or EGFR. Am. J. Surg. Pathol. 2006, 30, 1097-1104.

140. Heon, S.; Yeap, B.Y.; Lindeman, N.I.; Joshi, V.A.; Butaney, M.; Britt, G.J.; Costa, D.B.; Rabin, M.S.; Jackman, D.M.; Johnson, B.E. The impact of initial gefitinib or erlotinib versus chemotherapy on central nervous system progression in advanced non-small cell lung cancer with EGFR mutations. Clin. Cancer Res. 2012, 18, 4406-4414.

141. Nguyen, D.X.; Chiang, A.C.; Zhang, X.H.; Kim, J.Y.; Kris, M.G.; Ladanyi, M.; Gerald, W.L.; Massague, J. WNT/TCF signaling through LEF1 and HOXB9 mediates lung adenocarcinoma metastasis. Cell 2009, 138, 51-62.

142. Colone, M.; Calcabrini, A.; Toccacieli, L.; Bozzuto, G.; Stringaro, A.; Gentile, M.; Cianfriglia, M.; Ciervo, A.; Caraglia, M.; Budillon, A.; et al. The multidrug transporter P-glycoprotein: A mediator of melanoma invasion? J. Invest. Dermatol. 2008, 128, 957-971.

143. Linger, R.M.; Keating, A.K.; Earp, H.S.; Graham, D.K. TAM receptor tyrosine kinases: Biologic functions, signaling, and potential therapeutic targeting in human cancer. Adv. Cancer Res. 2008, $100,35-83$.

144. Wilhelm, I.; Nagyoszi, P.; Farkas, A.E.; Couraud, P.O.; Romero, I.A.; Weksler, B.; Fazakas, C.; Dung, N.T.; Bottka, S.; Bauer, H.; et al. Hyperosmotic stress induces axl activation and cleavage in cerebral endothelial cells. J. Neurochem. 2008, 107, 116-126.

145. Holland, S.J.; Pan, A.; Franci, C.; Hu, Y.; Chang, B.; Li, W.; Duan, M.; Torneros, A.; Yu, J.; Heckrodt, T.J.; et al. R428, a selective small molecule inhibitor of Axl kinase, blocks tumor spread and prolongs survival in models of metastatic breast cancer. Cancer Res. 2010, 70, 1544-1554.

146. Lin, Q.; Balasubramanian, K.; Fan, D.; Kim, S.J.; Guo, L.; Wang, H.; Bar-Eli, M.; Aldape, K.D.; Fidler, I.J. Reactive astrocytes protect melanoma cells from chemotherapy by sequestering intracellular calcium through gap junction communication channels. Neoplasia 2010, 12, 748-754.

147. Kim, S.J.; Kim, J.S.; Park, E.S.; Lee, J.S.; Lin, Q.; Langley, R.R.; Maya, M.; He, J.; Kim, S.W.; Weihua, Z.; et al. Astrocytes upregulate survival genes in tumor cells and induce protection from chemotherapy. Neoplasia 2011, 13, 286-298. 
148. Menter, D.G.; Herrmann, J.L.; Nicolson, G.L. The role of trophic factors and autocrine/paracrine growth factors in brain metastasis. Clin. Exp. Metastasis 1995, 13, 67-88.

149. Seike, T.; Fujita, K.; Yamakawa, Y.; Kido, M.A.; Takiguchi, S.; Teramoto, N.; Iguchi, H.; Noda, M. Interaction between lung cancer cells and astrocytes via specific inflammatory cytokines in the microenvironment of brain metastasis. Clin. Exp. Metastasis 2011, 28, 13-25.

150. Sierra, A.; Price, J.E.; Garcia-Ramirez, M.; Mendez, O.; Lopez, L.; Fabra, A. Astrocyte-derived cytokines contribute to the metastatic brain specificity of breast cancer cells. Lab. Invest. 1997, 77, 357-368.

151. Coussens, L.M.; Werb, Z. Inflammation and cancer. Nature 2002, 420, 860-867.

(C) 2013 by the authors; licensee MDPI, Basel, Switzerland. This article is an open access article distributed under the terms and conditions of the Creative Commons Attribution license (http://creativecommons.org/licenses/by/3.0/). 